\title{
Procesos creativos en la configuración de ámbitos interiores
}

Mario Ernesto Esparza Díaz de León

$\mathrm{T}$ odo proyecto habitativo comienza a existir desde el momento en que el ser humano reconoce su necesidad de pertenecer y de ser en este mundo; como lo menciona Nicola Flora (2007): construir el espacio de habitar es experiencia primaria e ineludible de la actividad humana. Así de trascendente es la configuración de la espacialidad en la interioridad creativa del hombre, la construcción de un universo cargado de simbolismos, deseos o aspiraciones resultantes de una memoria de la vida cotidiana.

El propósito de este artículo es el poder compartir las estrategias metodológicas: la incorporación de la experimentación sensorial, la observación y el uso de la bitácora de campo, implementadas por el doctor Mario Esparza Díaz de León y la maestra Ana Luz Verdín Vargas, en el desarrollo del proceso creativo para la configuración de un proyecto de diseño en el Taller de Diseño de Espacios Habitacionales del séptimo semestre de la Licenciatura en Diseño de Interiores, durante el semestre enero-junio de 2016.

\section{La configuración de ámbitos interiores}

El acto creativo, inherente al ser humano, libre e íntimo, como indica Díaz Curiel (2013), representa para el diseñador de interiores la configuración de ámbitos particulares fundamentados en las relaciones de los seres humanos, los habitantes con el mismo espacio y sus componentes tangibles e intangibles: objetos, macro objetos, equipamiento, accesorios decorativos, tradiciones, rituales, sonidos, colores, olores, entre otros.

Para la Licenciatura en Diseño de Interiores de la Universidad Autónoma de Aguascalientes (UAA), desde su fundación, el proceso metodológi- co para la configuración y ejecución de ámbitos y ambientes interiores ha representado un constante punto de interés, particularmente por ser un programa educativo pionero en la entidad y que, por lo mismo, se ha ido formando paulatinamente con la participación de docentes especialistas en el área, ${ }^{1}$ con la perspectiva específica de lo "íntimo o lo interior", lo cual ha permitido desarrollar e implementar conceptos a una escala pertinente del interiorismo arquitectónico: el detalle. Ya en su última revisión, el plan de estudios de esta licenciatura plantea la necesidad de una "metodología sistemática y coordinada, incluida la investigación, el análisis y la integración del conocimiento en el proceso creativo" (UAA, 2013: 5-6).

Al abordar el estudio del espacio interior, es obligatoria, por naturaleza misma de la disciplina, la comprensión dimensional del concepto de espacialidad, que anteriormente (producto del desconocimiento) estaba ligada estrictamente a la exterioridad física y superficial de sus componentes, obedeciendo al voluble sentido de la vista y del "buen gusto".

$\ll$ Para el proyecto de interiores, es necesario adquirir una visión

holística de la habitabilidad; un marco conceptual de significación que permita

al diseñador establecer criterios o posturas de configuración. $\gg$

1 Ya trabajado desde 2004 por la Academia de Diseño de Interiores con la maestra Blanca Ruiz Esparza, y actualmente profundizado mediante el trabajo colaborativo entre la Academia de Diseño de Interiores y el Comité de Implementación y Seguimiento del Plan de Estudios 2013 de la Licenciatura en Diseño de Interiores. 

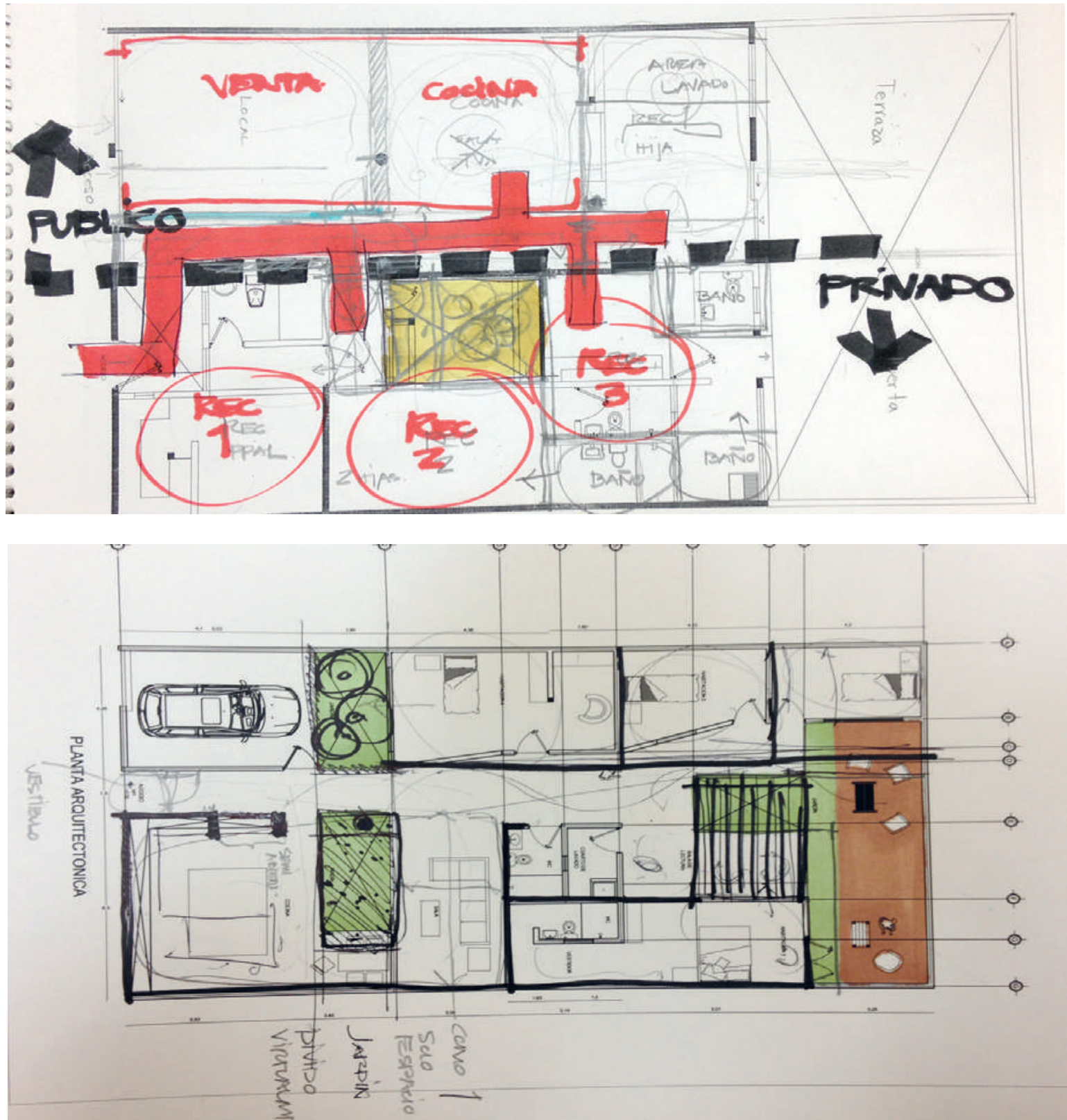

Imágenes 1 y 2. Fotografías del análisis de trabajo en las bitácoras de campo de las alumnas Estefanía Sáenz Ramírez y Ariadna Rizo Maldonado. Revisado por Mario Ernesto Esparza Díaz de León (2016).

\section{El proceso creativo}

Para iniciar un proyecto de interiores, es necesario adquirir una visión holística (incluyendo la actitud o postura) de la habitabilidad, razón fundamental de la espacialidad interior, el buan-bauer de M. Heidegger (Franck, 2011) en el sentido de construcción, de permanencia o residencia, para poder considerar los factores que inciden en dicha construcción: un marco conceptual de significación que permita al diseñador establecer criterios o posturas de configuración.

Para la configuración de los ámbitos interiores domésticos, se estableció una estructura integral dividida en tres procesos:

1. Planteamiento, investigación y fundamentación

El estudiante se introduce al tema de estudio, en este caso el espacio habitacional, mediante la in- 
vestigación de definiciones, generalidades históricas, esquemas de configuración y conceptos pertinentes como la domesticidad, el confort, lo íntimo y lo privado, entre otros, a través de dos ejercicios: la lectura de bibliografía pertinente y específica, determinada por el profesor para la definición de $\operatorname{conceptos}^{2}$, y el análisis particular de su vivienda: sensorial y significativo; todo el proceso de análisis se trabaja en una bitácora de campo (Imágenes 1 y 2) que le permite desarrollar el ejercicio práctico de los esquemas, mapas mentales y abstracción de conceptos: ideas, bocetos y anotaciones que se diluyen ante la confianza de la memoria.

De manera paralela, se trabaja sobre la psicología perceptual e identidad del entorno habitable, particularmente del espacio interior donde se desarrolla el proyecto de diseño, mediante el levantamiento y análisis físico-técnico-memorial (elementos y componentes, instalaciones y equipamiento, tradiciones y rituales, entre otros), desde una perspectiva holística sensorial: vista, tacto, olfato, gusto, oído y memoria; categorizando la información mediante el uso de registros: acústico, escópico, somático y léxico, basados en el planteamiento realizado por Katia Mandoki (2009) en su libro Prácticas Estéticas e Identidades Sociales.

Es importante subrayar en este apartado la importancia de la observación, el cual es un factor relevante por la intangibilidad que conlleva el espacio interior: los momentos, las anécdotas, los recuerdos, los rituales, entre otros; como lo menciona María Isabel Alba (2016: 88):

Toda creación se apoya en una mirada atenta, que actúa como instrumento de conocimiento y de reflexión; una mirada activa y creadora, que contiene un pensamiento, pero también en unas manos que vuelcan estos pensamientos al papel y los materializan. En este sentido, la docencia de Proyectos debería contemplar como tarea fundamental la educación de la mirada, con el fin de que el alumno desarrolle una capacidad perceptiva que le lleve a abordar de una forma creativa todo proyecto de arquitectura.

2 El trabajo centrado en la construcción de marcos conceptuales (significaciones), le permite al estudiante generar un criterio y una postura de cómo intervenir el tema a diseñar.

\section{Interpretación y conceptualización}

Como consecuencia del proceso anterior, el estudiante realiza una interpretación teórico-práctica mediante el ejercicio de una hipótesis conceptual: una propuesta experimental formal (Imágenes 3, 4 y 5), basada en un planteamiento realizado por Lorraine Farrelly y Brown (2012) en su libro Materials and Interior Design, y fundamentada en un discurso teórico sólido, producto del análisis previo.

Lo interesante de esta etapa es que se realiza el ejercicio durante el desarrollo de la materia, donde los resultados son expuestos frente a la totalidad del grupo. Cada estudiante manifiesta su discurso y planteamiento hipotético espacial y, a su vez, se le cuestiona y retroalimenta, tanto por los profesores, como por los mismos compañeros de clase; ya Ricardo López y Gabriela Gómez (2016) resaltan la relevancia de la retroalimentación en los talleres de diseño como parte fundamental en los procesos de enseñanza-aprendizaje y su evaluación.

\section{Configuración de ámbitos y microambientes}

Para finalizar con este proceso creativo de configuración, el estudiante realiza ejercicios prácticos sobre la concepción de la estructura funcional del espacio habitable: la composición del espacio doméstico aplicando en primera instancia a conceptos de reinterpretación y resignificación de los mismos, en relación a las actividades realizadas en ellos. Este ejercicio le permite reflexionar en un sentido creativo sobre las diferentes posibilidades de solución ante la predominante idea de la casa estandarizada.

En esta etapa, el estudiante de Diseño de Interiores trabaja específicamente sobre el estudio y desarrollo de microambientes y sistemas de ámbitos, mediante el desarrollo de esquemas de servicio y funcionamiento, diagramas de relación y narrativas espaciales que se refieren a la estrecha relación entre el espacio, el objeto y el usuario y su escala paulatina; éste es el detonante principal en la configuración de un espacio interior.

En conclusión, la experiencia adquirida con la implementación de estos procesos metodológicos en el desarrollo del Taller de Diseño 


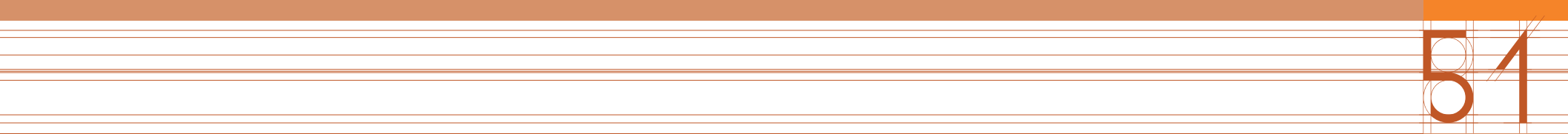

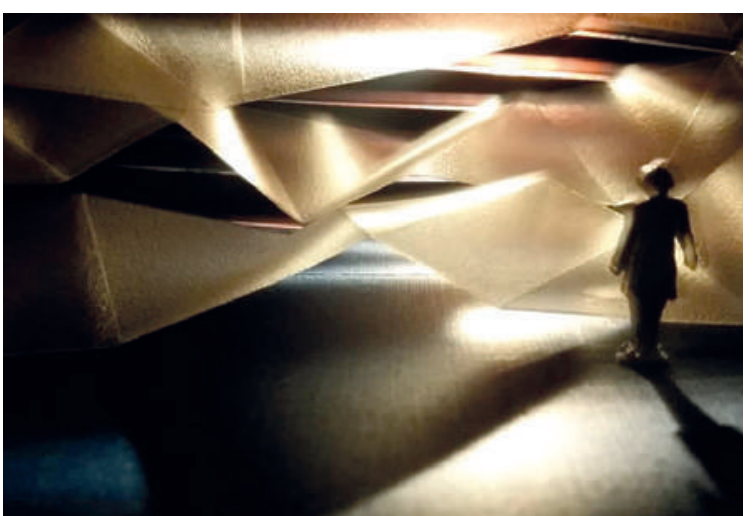
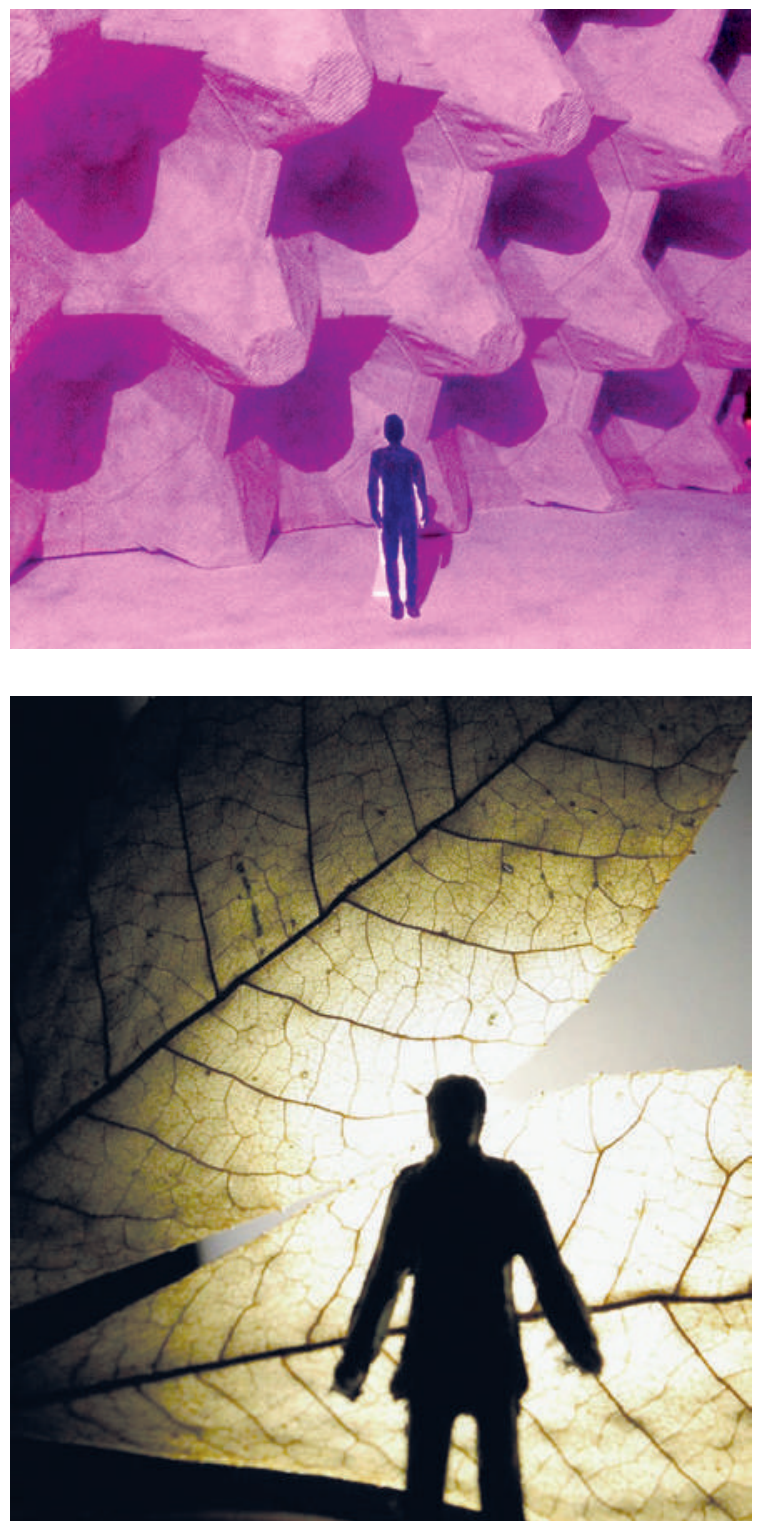

Imágenes 3, 4 y 5. (De arriba a abajo) Fotografías de Mayra Aguilera Lara, Mónica Castro Castro y Alba Mariana Díaz Márquez (2016), resultado de la "Experimentación en el espacio interior". de Espacios Habitacionales, nos permite, tanto a maestros como alumnos, profundizar en la especificidad y escala de la disciplina del Interiorismo y, sobre todo, el poder contribuir con cada uno de los profesores que conforman el programa educativo, en la construcción de una metodología integral del Diseño de Interiores en la Universidad Autónoma de Aguascalientes.

\section{Fuentes de consulta}

Alba, M. (2013). Manos que piensan. Reflexiones acerca del proceso creativo del proyecto de Arquitectura. Revista De EGA, (22), 96-203. España: UPV. Recuperado el día 03 de junio de 2016, en: http://bit.ly/2fktUfL.

Alba, M. (2016). La mirada atenta. Aproximaciones a la creación arquitectónica. Revista De EGA, 21(27), 88-95. España: UPV. Recuperado el día 12 de julio de 2016, en: http://bit. ly/2fDy7in.

Brown, R. (2012). Materials and interior design. Inglaterra: Laurence King Publishing.

Díaz, J. (2013). Proceso creativo, arte y psicopatología. Revista de la Asociación Española de Neuropsiquiatría, 33(120), 749-760. España: SCIELo. Recuperado el 18 de junio de 2016, en: http://scielo.isciii.es/pdf/neuropsiq/v33n120/original5.pdf.

Flora, N. (2007). Progettare, sperimentare, costruire. Quaderno di ricerche esperimentazioni sull'interno architettonico. Italia: Clean Edizioni.

Franck, D. (2011). Heidegger y el problema del espacio. México: Universidad Iberoamericana, A. C.

López, R. y Gómez, G. (2016). Retroalimentación: una práctica empática en los talleres de diseño. Revista Docere, (14), 7-10. México: UAA. Recuperado el 20 de julio de 2016, en: http://bit.ly/2cRzwvn.

Mandoki, K. (2009). Prácticas estéticas e identidades sociales. México: Siglo XXI.

Universidad Autónoma de Aguascalientes. (2013). Plan de estudios de la Licenciatura en Diseño de Interiores. México: UAA. 